\title{
Migrant Women's Perspectives on Reproductive Health Issues and Their Healthcare Encounters
}

\author{
Mirko Prosen \\ University of Primorska, Slovenia \\ mirko.prosen@fvz.upr.si
}

\section{Sabina Ličen}

University of Primorska, Slovenia

sabina.licen@fvz.upr.si

\section{Urška Bogataj}

University of Primorska, Slovenia

urska.bogataj@fvz.upr.si

\section{Doroteja Rebec}

University of Primorska, Slovenia

doroteja.rebec@fvz.upr.si

\section{Igor Karnjuš}

University of Primorska, Slovenia igor.karnjus@fvz.upr.si

Migration exposes women to greater health risks and health disparities. Healthcare professionals need to identify, prioritise and address these needs and risks in a holistic manner. The chapter explores migrant women's experiences with the health system and specifically their perspectives on reproductive health issues within the host country's healthcare system. A descriptive qualitative study using a qualitative content analysis approach was conducted in a maternity hospital in Slovenia. The purposive sample included $10 \mathrm{mi}-$ grant women. The analysis yielded two themes: (1) experiences, expectations and barriers of a different healthcare system; and (2) the impact of culturebased beliefs on women's reproductive health. The majority of the interviewed women felt they had received culturally responsive care, even though the language barrier was seen as one of the biggest obstacles in accessing healthcare. From the perspective of sexual and reproductive health, their migration was liberating for the women. Healthcare professionals need to learn more about cultural-based health practices since some of them are harmful to women and require their attention in the future.

\section{Introduction}

Migrants have had a considerable impact on population demographics in the European Union (EU) in the last decade. During this period, push and pull 
factors have changed dramatically, accompanied by new migration trends. Among others, migrant women are today slowly becoming the majority of migrants around the world and not just in the EU where it is estimated that women also make up a significant proportion of undocumented migrants (Jayaweera, 2018). The migration of women may be driven by individual factors, such as marital or reproductive status, education and skills, or by family or social factors like status or class (Fleury, 2016). In this context, migration can provide new opportunities for women either on their own or together with their spouses to improve their lives, escape oppressive social norms, and support children and other family members who are left behind. However, migration also exposes them to a series of vulnerable situations resulting from a precarious legal status, abusive working conditions, physical violence and health risks (de Leon Siantz, 2013; Fleury, 2016; Jayaweera, 2018).

Women's health risks related to migration vary. Migration may result in a worsening or an improvement of a woman's health. The resulting health impact of migration is generally determined by the conditions in which the migration occurred, the extent of integration, the woman's social status and the prevailing health conditions in the host country (Adanu \& Johnson, 2009; Hargreaves \& Friedland, 2013). Jayaweera (2018) listed multiple determinants of migrants' health status which indirectly or directly affect their health. These include biology, demography, socio-economic circumstances before, during and after migration, emigration policies in the sending countries and immigration and integration policies in the host countries, cultural traditions and cultural identity, social networks including transnational networks, length of residence in host countries, and impact of racism and discrimination. These and other determinants put women migrants at a disadvantage compared to male migrants for several reasons, where being both a woman and a migrant dominates. There is widespread evidence that women migrants face greater health disparities (Adanu \& Johnson, 2009; Hargreaves \& Friedland, 2013; Robertson, 2015), specifically greater health disparities related with sexual and reproductive health (Hargreaves \& Friedland, 2013; Merry, Vangen, \& Small, 2016; Perez Ramirez, Garcia-Garcia, \& Peralta-Ramirez, 2013; Reeske \& Razum, 2011; Saadi, Bond, \& Percac-Lima, 2015; Smith, LeVoy, Mahmood, \& Mercer, 2016). It has also been established that migrant women may often not have reliable access to healthcare or reproductive healthcare, which in turn negatively impacts maternal and perinatal outcomes (Fleury, 2016).

While most governments in the world recognise health as a basic human right and all EU member states have legally recognised the right to 
the highest attainable standard of health for everyone in their population (Pace, 2011), significant debates remain over the extent to which migrants share the same rights as non-migrants in relation to accessing healthcare. From this perspective, migrants clearly provide organisational challenges to healthcare systems across the EU member states since many of those systems are not prepared to give appropriate healthcare to so many culturally diverse patients. Any healthcare system's ability to respond within a reasonable time and holistically to migrant women's specific needs rests on its ability to identify and prioritise those needs and associated risks (Ruppenthal, Tuck, \& Gagnon, 2005). Exclusion in any way from healthcare means that women encounter delayed access to screening, treatment and care, limited access to contraception and pregnancy termination and heightened levels of discrimination and gender-based violence, all of which affects women's health and exacerbates health disparities (Smith et al., 2016).

When seeking to access the healthcare system, migrants, especially new arrivals, face barriers imposed by personal factors like age, sex, socio-economic status, ethnicity, language ability, proximity to healthcare services, social exclusion, health-seeking behaviour and health beliefs. In addition, barriers at the healthcare system level include public health policy and the legal status of migrants within the host country's health system, as well as specifics of the individual health system (Hargreaves \& Friedland, 2013). Hargreaves and Friedland (2013) also categorised key barriers in accessing healthcare services for newly arrived migrants by dividing them into two categories (Table 1). A similar division into two categories was presented by Nørredam and Krasnik (2011) where the first category 'formal barriers to access' was associated with health policies and the organisation of health systems. The second category 'informal barriers to access' was associated with language, communication, socio-cultural factors and 'newness' or the complex interaction of these factors.

By overcoming at least some of these barriers, healthcare professionals strive to ensure culturally sensitive healthcare for migrant women. Bjarnason, Mick, Thompson, and Cloyd (2009) emphasise it is imperative in serving the unique and diverse needs of patients, especially those who are most vulnerable, as women migrants are, that nurses, midwives, medical doctors and other healthcare professionals understand the importance of cultural differences by valuing, incorporating and examining their own health-related values and beliefs and those of their healthcare organisations, for only then can they support the principle of respect for persons and the ideal of transcultural care. It is a legal and moral obligation for all healthcare professionals 
Table 1 Key Barriers to Accessing Healthcare for Newly Arrived Migrants

\begin{tabular}{ll}
\hline Category & Barrier \\
\hline $\begin{array}{l}\text { System and } \\
\text { provider-level } \\
\text { barriers }\end{array}$ & Entitlement to publicly funded healthcare \\
& $\begin{array}{l}\text { Discriminatory practices and negative attitudes of frontline staff } \\
\text { Quality of care }\end{array}$ \\
\hline $\begin{array}{l}\text { Patient-level } \\
\text { barriers }\end{array}$ & Knowledge of health services and how to use them \\
& Adaptation to a new healthcare system \\
& Language barriers \\
& Asylum-seeker status \\
\hline
\end{tabular}

Notes Adapted from Hargreaves and Friedland (2013, p. 32).

to be culturally competent in order to provide high-quality care to patients from different cultural backgrounds (Prosen, 2018; Repo, Vahlberg, Salminen, Papadopoulos, \& Leino-Kilpi, 2017).

The aim of the study, as part of a large-scale EU-funded project (Crossborder network for migrant women: social integration, sexual and reproductive health - INTEGRA), was to explore the experiences of hospitalised migrant women and their encounters with healthcare professionals, as well as their perspectives on the care rendered that touches on reproductive health issues.

\section{Methods}

\section{Research Design}

A descriptive qualitative study using a qualitative content analysis approach was conducted in a maternity hospital in Slovenia (Gynaecological and Maternity Hospital Postojna). A descriptive qualitative approach is based on the general premises of constructivist inquiry and is often used in studies which are descriptive in nature, especially in examining healthcare phenomena (Polit \& Beck Tatano, 2014; Sandelowski, 2000). This research design was identified as important and appropriate for a research question focused on exploring the who, what and where of events or experiences and gaining insights into poorly understood phenomena (Kim, Sefcik, \& Bradway, 2017).

\section{Study Setting}

The Slovenian healthcare system is a public service organised on three levels that are mainly funded by the Health Insurance Institute of Slovenia. Hospital treatment is provided on secondary and tertiary levels in general and specialised hospitals located around Slovenia. Besides hospital treatment, the secondary level ensures specialised ambulatory care, which differs from am- 
bulatory care given at the primary level by treating more complicated diseases, offering more advanced diagnostics and methods of treatment.

There are 14 maternity clinics in Slovenia. Women in Slovenia have the right to use contraception, pregnancy and childbirth healthcare and the right to terminate a pregnancy (in accordance with the country's legislation). The majority of healthcare for women is, of course, delivered as primary care. Healthcare professionals included in caring for women's health are medical doctors, midwives and nurses.

\section{Participants}

Purposive sampling was used to select the participating women. This nonprobability sampling method was chosen since it allows the researcher to select participants based on a personal judgement about who will be the most informative, e.g. information-rich cases who are good informants about the phenomenon under investigation (Polit \& Beck Tatano, 2014). The sample included 10 migrant women who had been admitted to the hospital from the end of January till the end of April 2018. The criteria set for being included in the sample were, apart from a willingness to participate, the ability to overcome the language barrier and to understand each other during the interview and the saturation of data. The latter is reached when no new analytical information appears which would further the explanation of the phenomena (Moser \& Korstjens, 2018).

\section{Data Collection}

The data were collected using semi-structured interviews. This approach enables the researcher to follow the course of the content, reduce bias and at the same time maintain the same stimulus in all interviewees (Quinn Patton, 2015). The interview guide was based on an Italian questionnaire used in a previous study (AIDOS, ADUSU, \& Culture aperte, 2009). The questionnaire was translated from Italian into Slovenian by a researcher fluent in Italian and with expertise in healthcare. This was followed by the work of an expert group which over two rounds evaluated the translation, clarity and understanding of the questions. The questions were modified so that they suited the form of an interview guide and the research design used, as well as the cultural context in Slovenia. Examples of interview probes on healthcare are 'Tell me about the healthcare system in your home country' or 'Tell me about your experiences with the healthcare system in Slovenia' and on healthcare professionals 'Tell me about your gender preferences regarding the healthcare provider.'

Prospective participants were personally invited and given an exhaustive 
explanation of the study objectives and the methods used in a language they understood. Those who decided to participate were once again told about the purpose, research methods, ways of ensuring anonymity and confidentiality, and the possibility of feedback. Women were also informed of the opportunity to withdraw from the interview at any time. All the women had to give their written consent prior to the interview. For three women, the spoken language was Slovenian, for three it was English, for another three Slovenian and partially Serbian, and for one Slovenian and partially English. In no case was an interpreter or translator not present. On average, an interview lasted 38.30 minutes. The shortest was 18 minutes and the longest 71 minutes. The interviews were conducted in hospital rooms, paying special attention to the confidentiality and well-being of the participants. Each interview was audio-recorded and each participant was given a unique code.

\section{Data Analysis}

The interviews were transcribed verbatim. Names of persons, places and institutions were anonymised. After transcribing the interviews, the transcripts were once again checked against the audio-recorded transcripts. A qualitative data analysis was performed using the computer software program NVivo (version 12). Before the analysis commenced, the similarity metric of individual cases was analysed using cluster analysis and Pearson's coefficient. According to the highest $(r=0.907)$ and lowest $(r=0.745)$ values of Pearson's correlation coefficient, it can be argued that there is a positive and strong relationship between individual cases.

The transcripts were subjected to thematic analysis (Flick, 2002; Gibson \& Brown, 2009; Matthews \& Ross, 2010; Riessman, 2008; Sandelowski, 2000; Smythe, 2012) which relates to the process of analysing data in relation to communalities, differences and relationships. Data were reduced as part of the analysis. Data reduction is a form of analysis that sharpens, sorts, focuses, discards and organises data in such a way that 'final' conclusions may be drawn and verified (Miles \& Huberman, 1994, p. 11). The analysis followed these steps: the transcripts were read several times to obtain a clearer picture of the phenomena under study, the data were coded, codes were merged into sub-themes, and themes were formed on the basis of categories (Flick, 2002; Steen \& Roberts, 2011).

\section{Ethical Consideration and Funding}

The study was conducted in accordance with the Helsinki-Tokyo Declaration (World Medical Association, 2013), the Code of Ethics for Nurses and Nurse 
Assistants of Slovenia (Zbornica zdravstvene in babiške nege Slovenije, 2014) and the recommendations issued for ethics in qualitative research (British Sociological Association, 2002). The study was approved by the National Medical Ethics Committee (26.10.2017; No. 0120-544/2017/7). In addition, permission was obtained from the hospital.

The study formed part of the INTEGRA project and was co-funded by the cross-border co-operation Programme Italy-Slovenia 2014-2020 financed by the European Regional Development Fund.

\section{Findings}

\section{Background Information on the Participating Women}

The average age of the interviewees was 30.5 ( $S D=5.68$ ) years, with the youngest being 22 and the oldest 37 years. Three interviewees had migrated from Bosnia and Herzegovina, two from Russia and Serbia, one each from Ukraine, Kosovo and Iran. All, except one, had migrated directly from their home country to Slovenia. The reason for migration was for six of them to re-join their family (in most cases, their spouse who was 'work migrant' in Slovenia). Three women had migrated for work opportunities and one to be married. Two women had finished vocational education, four women secondary, one high school and three university level. Their lives in Slovenia are very much defined by their living conditions. More than half $(n=6)$ of them live in a rented apartment in an urban area. The average household includes $3.2(\mathrm{SD}=0.91)$ members. All interviewees, with the exception of one, have health insurance in the Republic of Slovenia. From the perspective of obstetrics anamnesis, eight women were primipara and two were multipara. Nine of them gave birth in 2018 in Slovenia. The average age of the first-time mothers was $28.80(S D=6.54)$ years. At the time of giving birth, the youngest was in their 205 and the oldest was aged 37 years.

\section{Main Themes}

Two themes emerged under 'Migrant women's perspectives on reproductive health issues and their encounters within healthcare' (Table 2). The first theme 'Experiences, expectations and barriers of a different healthcare system' summarises the migrant women's views on the healthcare delivered in their home country and later on in the host country. Their stories brought to the fore their perceptions of inequality in the home country and experiences and barriers with the host country's healthcare system. The second theme 'The impact of culture-based beliefs on women's reproductive health' 
Table 2 Identified Codes, Sub-Themes and Themes

\begin{tabular}{|c|c|c|}
\hline Codes & Sub-themes & Themes \\
\hline $\begin{array}{l}\text { Respecting a woman's cultural background while } \\
\text { delivering healthcare ensures a positive patient ex- } \\
\text { perience }\end{array}$ & \multirow{4}{*}{$\begin{array}{l}\text { Considering a } \\
\text { woman's cultural } \\
\text { background while } \\
\text { delivering health- } \\
\text { care in the host } \\
\text { country }\end{array}$} & \multirow{6}{*}{$\begin{array}{l}\text { Experiences, ex- } \\
\text { pectations and } \\
\text { barriers of a differ- } \\
\text { ent healthcare sys- } \\
\text { tem }\end{array}$} \\
\hline $\begin{array}{l}\text { Language barrier influences access to healthcare } \\
\text { services }\end{array}$ & & \\
\hline $\begin{array}{l}\text { Perceived absence of prejudice and discrimination } \\
\text { in interaction with healthcare professionals }\end{array}$ & & \\
\hline $\begin{array}{l}\text { Recognised quality of the healthcare system in host } \\
\text { country compared to the home country }\end{array}$ & & \\
\hline $\begin{array}{l}\text { Inequalities in accessing healthcare services have an } \\
\text { important impact on health }\end{array}$ & \multirow{2}{*}{$\begin{array}{l}\text { Health disparities } \\
\text { persist in the home } \\
\text { country }\end{array}$} & \\
\hline $\begin{array}{l}\text { Provision of care for women's reproductive health } \\
\text { does not follow advances concerning patient safety }\end{array}$ & & \\
\hline $\begin{array}{l}\text { Women's contraception is more or less based on a } \\
\text { joint decision of the partners }\end{array}$ & $\begin{array}{l}\text { Women's au- } \\
\text { tonomy and the } \\
\text { right to reproduc- } \\
\text { tive freedom }\end{array}$ & \multirow[t]{2}{*}{$\begin{array}{l}\text { Impact of culture- } \\
\text { based beliefs on } \\
\text { women's reproduc- } \\
\text { tive health }\end{array}$} \\
\hline Health- and illness-related traditions and customs & $\begin{array}{l}\text { Health-related } \\
\text { practices }\end{array}$ & \\
\hline
\end{tabular}

illustrates women's right to reproductive freedom and the ways that culture, along with tradition, influence health-related behaviour.

\section{Experiences, Expectations and Barriers of a Different Healthcare System}

The first theme revolves around two sub-themes showing the comparison of experiencing healthcare services in the home and host country. It was evident that socio-economic status in the home country was a determining factor in accessing high-quality healthcare and therefore often the reason for health disparities, while accessing healthcare services in the host country was often accompanied by a language barrier which functioned as a barrier to delivering culturally congruent healthcare. Each of these sub-themes is explained in more detail below.

\section{Considering a Woman's Cultural Background in Delivering Healthcare in the Host Country}

Almost all the interviewees emphasised that their cultural background had been respected and not rejected when in contact with healthcare professionals. The women's description shows that healthcare professionals were 
culturally sensitive in providing care. Some women were even surprised that their autonomy had been respected since it was unexpected. One interviewee from Ukraine said:

I was shocked [...]. When you are pregnant it is important that you are treated well and you are 'heard.' Both midwives present at my childbirth did what I asked them to do. I actuality cried, because it was like a dream come true. [INTE_32_1_UKR]

Although the majority of women considered the healthcare delivered to have been culturally appropriate, two of them had negative experiences. A migrant woman from Serbia described her story of being pregnant. Her gynaecologist at the primary level suggested the maternity clinic she works at, despite the woman's choice to give birth in another maternity clinic. After the woman insisted on going to a maternity clinic of her choice, the gynaecologist in her own words was 'feeling very insulted' and said:

You from foreign countries, you always want to do something on your own, you don't listen to advice. [INTE_22_1_SRB]

A woman from Kosovo described her experience with nurses because she felt they perceived her as different. She said:

Some nurses didn't want to speak to me in English. They looked at me as if they were angry at me. I do not know why. Perhaps because I'm a foreigner. We are all people [...] even though I'm not Slovenian. If I saw someone who needs help, I would be glad to help him [...] even though he or she is not Albanian, but he is human after all. [INTE_23_1_KOS]

The language barrier is indeed an overwhelming barrier for migrants and, as it seems, also for healthcare professionals. Women's experiences vary, from those who did not have any communication problems when in contact with healthcare professionals to those who had experienced some problems like the woman above. The first group of women prevailed and they did not stress the need for an interpreter or translator. These also included newly arrived migrant women, but because their language group (Slavic languages) was similar to the Slovenian language the language barrier was not great. On the contrary, a woman from Kosovo revealed that interpreting would be a good solution since Slovenians have trouble understanding Albanian: 
It is easier if you have with you an interpreter [...] the Albanian language is difficult to learn. It is hard to get someone who understands. [INTE_23_1_KOS]

A woman from Russia described her experience when hospitalised for the first time in Slovenia. She explained that the word 'better' (in Slovenian 'boljše') means bigger in Russian (in Slovenian 'večje').

[...] and then the nurse asked me about the presence of pain: 'Is it better?' and I said: 'Yes.' And then she left the room. I did not get the analgesics at that time. This happened only once and never again. [INTE_37_1_RU]

Another aspect of ensuring culturally sensitive care is the absence of prejudice and discrimination among healthcare professionals towards the patients they care for. The interviewees did not report any negative experiences with healthcare professionals, although one of them, a woman from Serbia, pointed out that 'rude people exist everywhere in the world, in the home country as well as in the host country.' She also described her encounter with a female gynaecologist, since she had desired to give birth in a maternity clinic different to that suggested by the gynaecologist (the woman further explained that her gynaecologist also works there part time). The woman declined and her gynaecologist gave the following answer:

'Yes, you foreigners, you always want to do things your way, you do not listen to advice.' I was quite offended and I mentioned to her that if my last name were the same as my husband's we would not be having this conversation. [INTE_22_1_SRB]

Despite this experience, and considering situations that the women did not mention, they all recognised the healthcare system in Slovenia as being superior to the healthcare system in their home country.

Slovenia has a good health system. In Kosovo, the physicians are good, but the system does not function. [...] we receive much more in Slovenia from the health system than we did in Kosovo. [INTE_23_1_KOS]

Healthcare is a disaster. There is no health system in Bosnia. [INTE_35_3 - BIH]

I believe Slovenia has a high-quality health system. In my opinion, the system here is even better than in Germany. [INTE_36_1_RU] 
The quality of the healthcare services in Slovenia and the existence of health disparities in the home country's healthcare system were reported by some interviewees as reasons that women from South-east Europe migrate to Slovenia. This issue was further elaborated by the interviewees from the perspective of the health disparities they had encountered while (they or their family members were) accessing healthcare services in their home country.

\section{Health Disparities Continue in the Home Country}

The majority of interviewees perceived the public healthcare system in their home country as unjust since high-quality care depended on the economic standard of the individual. This was noted by women from Ukraine, Serbia, Kosovo, and Bosnia and Herzegovina. Public healthcare services were experienced as services low in quality, as services lacking appropriate staff, standards and resources, while the private sector was described as the opposite.

We pay for healthcare services. We have health insurance. It's about EUR 10 per year, but they treat you as if you do not have any insurance at all. You are always first and if you do not pay you are always last. [INTE_35_3_BIH]

The women had greater trust in the private sector:

We have state health insurance. If possible, I preferred to use the services offered by the private sector. The state health institutions are crowded, without friendly staff. Communication is important. The truth is that I do not trust state health institutions so much. [INTE_36_1_RU]

The difference between private and public health services? In the private sector, you have to pay, but the services provided are higher in quality than in the public sector. [INTE_32_1_BIH]

Health disparities arose from the financial constraints of individuals, yet even with a lack of financial resources women and their families tried to find a way to better health. As seen, the situation in the described healthcare system was worsened by the fact that medications also had to be paid for. Even medications whose application and use are (and should be) limited to healthcare institutions are only available in pharmacies and must be purchased.

In Slovenia, you cannot get medication without a prescription. In Kosovo, we can have any medication without a prescription. You can take 
whatever you want. Perhaps not everything but, [...] when I had trouble with tonsillitis, I went to see to a physician working in the private sector. He sent me off to buy infusion, injections and an infusion set from the pharmacy. [INTE_23_1_KOS]

Corruption is another element of healthcare services and a further aspect or consequence of health disparities which considerably affects people's lives and health. A woman from Serbia described:

From another perspective, the public sector works by the same rules as the private one. If you bring them money, you will be taken care of, no matter what. My father broke a leg 10 years ago and, even though he was insured, my grandfather had to pay for his operation because the doctor knew he worked in Germany. My grandfather had to take the doctor to the store so that he could buy whatever he wanted. So [...] if you are poor, it's better that you don't go to the doctor. [INTE_22_1_SRB]

Women's health is also exposed to such health disparities and socioeconomic status is a powerful predictor of women's health. Two women from Bosnia and Herzegovina stated:

I went to a gynaecologist in both a public and private institution. In the private institution, I paid for the services, but I believe they were performed better. [INTE_25_3_BIH]

I can go to a public institution for a gynaecological examination but still, if you do not pay, no one will take a look at you. [INTE_32_1_BIH]

Healthcare services during childbirth seem to be limited in the public health institutions of some interviewees' countries of origin. A woman from Kosovo who gave birth in Slovenia said:

[...] I couldn't do it without an epidural. The physician (a woman) explained. I was scared [...] I'm glad I decided on an epidural (in Slovenia). I know that if I had given birth in Kosovo it would have been terrifying. [INTE_23_1_KOS]

A similar story was told by a woman from Bosnia and Herzegovina concerning prenatal check-ups as she experienced them in Slovenia. 
[...] in Bosnia some check-ups during pregnancy are only administrative in nature. It's not like in Slovenia. I tell you, it is better here (in Slovenia). [INTE_35_3_BIH]

Freedom of reproductive choice in countries where contraceptives must be purchased privately is particularly challenged, with serious consequences for women's lives, ranging from abortion to social marginalisation. One interviewee from Bosnia and Herzegovina (INTE_25_3_BIH) admitted that 'there was little knowledge about contraceptive methods among her friends' and that 'one's income limits the use of contraceptive pills.' In some countries, the different possibilities of contraception are also very limited.

In Slovenia, more kinds of contraceptives are available than in Bosnia. [INTE_25_3_BIH]

The practice of privately paying for oral contraceptives was also pointed out by a woman from Russia:

I was taking the same contraceptive pills in Russia as I'm taking now in Slovenia; however, I had to buy them in Russia. [INTE_37_1_RU]

At the end, this was seen as just one aspect of women's reproductive freedom. The women also described other factors that shape their right to use contraceptives and exercise their autonomy over reproductive freedom.

\section{The Impact of Culture-Based Beliefs on Women's Reproductive Health}

The second theme focuses on the culture-based beliefs surrounding women's health in relation to women's autonomy and their right to reproductive freedom. Societal expectations concerning reproduction and women's role in this process are challenging not only for women migrants in countries where reproductive freedom is fully exercised but also for societies themselves being challenged by the need to protect individuality as well as respect individual culture.

\section{Women's Autonomy and the Right to Reproductive Freedom}

Most interviewees stated they had used contraceptives in the past and some will probably continue to do so in the future. Yet they believe the decision for a woman to use contraceptives should be made together with the partner. All women confirmed that their partner was not opposed to the idea of using contraceptives, except in one case. 
My husband does not support the use of contraceptives. [...] with us, the husband decides about contraception use. [INTE_35_3_BIH]

Even though some of the migrant women are Muslim, it seems that religion does not impact reproductive freedom as much as one would expect. A woman from Iran, for example, noted:

Contraception is, of course, available in Iran. They both (the husband and wife) decide if they want to use it, if they want to have more children or not. [INTE_33_1_IR]

\section{Health-Related Practices}

Besides contraception, to treat gynaecological problems some women use complementary and alternative medicine methods. Certain methods may be hazardous to their health:

I use homoeopathic medicines and other herbs. In Slovenia, they are hard to get. It is easier in Ukraine, although some time ago they were forbidden for use. Today, they are available again in Ukraine. [INTE_32_1 _UKR]

A woman from Russia described a similarly hazardous experience involving oral contraceptives:

I talked to my friends from Russia living here in Slovenia. They bring something (meaning medication) from Russia, but I'm not sure whether I will still need contraception or not (laughs). [INTE_37_1_RU]

On the other hand, a few women only use medications prescribed by a medical doctor (school medicine) or over-the-counter medicines available in pharmacies. The use of such medicines ranges from occasional use in accordance with the prescribed intake regime to excessive use:

When I have PMS (premenstrual syndrome) [...] it's always unbearable and at that time l eat quite a lot of analgesics (names an analgesic that is available over the counter). [INTE_22_1_SRB]

\section{Discussion}

Evidence from this study focused on women's description of their experiences as patients in the health system of their host country (while looking 
back and comparing the care given in their home country) from the perspective of barriers to accessing healthcare. This study also explored the impact of the identified barriers on women's sexual and reproductive issues. As has been established, migrant women's health and well-being are very much determined by the societal factors surrounding the migration process as well as integration. However, their health status prior to their migration, namely, while still living in their home country, was subject to health disparities that largely derived from their socio-economic standing and gender-determined roles.

Due to unpleasant experiences as patients with their home country's health system, it seems that some women had low expectations of the health system in Slovenia. It came as a surprise later for them that healthcare in Slovenia may be described as high quality and, for all of them, a free service provided by the state. As part of this system, their encounters with healthcare professionals were perceived as culturally sensitive or responsive. A culturally responsive healthcare encounter requires the provider to take steps to moderate the power differential in order to form a more balanced partnership or therapeutic alliance with the patient. Even though any encounter in the context of diversity requires cultural responsiveness to be successful, mistakes in communications during the delivery of healthcare can be damaging due to the power differential between the provider and the recipient of care (Dreachslin, Gilbert, \& Malone, 2012). The latter was quite noticeable in two cases where women confided their experience. Yet, it should be emphasised that cultural responsiveness does not mean that 'anything goes' and does not require the healthcare provider to accommodate everything the patient wants (Dreachslin et al., 2012; Leininger, 2002). For example, Leininger (2002) states the focus of decision-making should include: (1) cultural care preservation, also known as maintenance; (2) cultural care accommodation, also known as negotiation; and (3) cultural care re-patterning or re-structuring.

Almost all of the interviewees reported that they did not feel discriminated by healthcare professionals due to their cultural background or their social status in the host country's health system. The right to access free healthcare services in the host country is insufficient for ensuring actual use of healthcare (Hargreaves \& Friedland, 2013). Healthcare professionals must therefore strive to deliver culturally responsive or congruent care for which cross-cultural competencies are essential. Cross-cultural competencies are one of the main ingredients in narrowing the health disparities gap as healthcare services which are respectful and responsive to the healthcare beliefs, practices, cultural and linguistic needs of a wide range of patients can con- 
tribute to positive health outcomes (Andrews \& Boyle, 2012). The implications for clinical practice derived from these findings point out to more intensive attempts to further develop cross-cultural competencies among healthcare professionals where, among other methods, transcultural education makes a significant contribution (Prosen, 2018).

A consistent finding is that the language barrier and trouble communicating with healthcare professionals continue for almost every woman interviewed, especially the new arrivals. Communication difficulties shape women's overall experience with a health system and directly negative impact her care and constitute a key factor in delayed diagnosis (Hargreaves \& Friedland, 2013). Women migrants who do not speak the native language and those from less affluent parts of the world are at increased risk of higher maternal morbidity and mortality and poor perinatal outcomes (Smith et al., 2016). For women coming from the former Yugoslav republics or women from Russia or Ukraine with which we share the Slavic language group, the Slovenian language sounded familiar, although women with an Albanian background had great difficulties establishing understandable communication with healthcare professionals. Among the interviewees, especially women from Kosovo who spoke Albanian expressed the need for an interpreter. This, of course, raises a few questions that deserve special attention when discussing the use of interpreters in gynaecology and obstetrics settings. The question of organising and financing such services should not be overlooked, although the question is related to the fact that sexual and reproductive health is still very much considered a societal taboo and under the influence of cultural traditions and practices. Some women may therefore feel unable to freely discuss their sexual and reproductive needs, making it harder for healthcare professionals to determine and provide appropriate care (Mengesha, Perz, Dune, \& Ussher, 2018). Professional interpreters are needed, albeit proficiency in the native language is not enough by itself and should also include, besides cultural knowledge, knowledge about privacy and confidentiality issues, knowledge about the health system etc. It should also be emphasised that effective communication between providers and patients requires attention to be paid to the cultural dimensions of not only verbal (or nonverbal) communication but also written communication, including health education materials, information related to the treatment plan and a patient's diagnosis (Dreachslin et al., 2012).

When women started elaborating more about healthcare services and encounters with healthcare professionals in their home country in comparison to Slovenia, it emerged that they had faced many health disparities in 
their home country based on their socio-economic status. That is why all the women recognised that superior healthcare services are delivered by the health system in Slovenia. Due to the women's previous experiences in their home country, the key element characterising healthcare services in Slovenia as superior was that they did not have to pay to obtain good quality services. It seems the public health policy in Slovenia works for migrant women, although in some cases inadequate health literacy was clearly present. Health literacy implies the achievement of a certain level of knowledge, personal skills and confidence to be able to take action to improve personal and community health (Tsai \& Lee, 2016). A lower level of health literacy was clearly noticeable among the newly arrived women. Inadequate health literacy may limit migrants' ability to take full advantage of health information and thus the services provided by the health system to make appropriate health decisions in the host country (Tsai \& Lee, 2016).

The women also recognised the quality of care related to reproductive health in the host country. As established in previous research (Reeske \& Razum, 2011; Smith et al., 2016), perinatal and maternal morbidity and mortality among migrant women are usually high. The migrations to that extent made the women more aware of their possibilities regarding reproduction and the freedom to choose. Religion did not, at least not directly, constrain the women's autonomy for reproductive freedom, although it is not easy to separate religion from sexuality and reproductive health. All major religions offer a distinct belief system which aims to guide devout followers in sexual and reproductive matters (Arousell \& Carlbom, 2016). Other culturally based traditions, such as inappropriate use of treatment methods or medications used for treatment, may also contribute to developing practices that harm women's reproductive health. For some, these practices seem to continue in the host country and this further supports calls for activities to increase health literacy among migrant women.

In qualitative research, the data as well as the conceptualised findings are prone to subjectivity. However, they allow an insight into migrant women's experiences with healthcare services in the host country from the sexual and reproductive health perspectives and have helped enrich other parts of large-scale research within the INTEGRA project. The study was also conducted in one hospital only, which could limit the responses obtained and the purposive sample could entail selection bias, yet the women selected for the interviews who had no difficulties communicating and expressing themselves in English or in a language familiar to the interviewer (Serbian). Future research should focus on exploring culturally based practices related to sex- 
ual and reproductive health, health literacy among newly arrived migrant women and those living in the host country for some time, gender-related barriers to accessing healthcare services along with re-examining ways to overcome the language barrier in the health system. Epidemiologic studies are also needed to determine the impact of health disparities on maternal morbidity and the mortality and perinatal outcomes of migrant women.

\section{Conclusions}

Migrant women form one of the most vulnerable and marginalised population groups, often excluded from healthcare services by a complex set of reasons, being either cultural, gender-related or based on their social status. Migrant women's health is much more challenged than men's, and not just during migration and arrival as shown by the study, and particularly so if we discuss sexual and reproductive health. Healthcare professionals have an important role in recognising health disparities and the diverse needs of migrant women deriving from their cultural background. Cultural responsiveness or cultural sensitivity must therefore become an imperative which obliges healthcare professionals to deliver culturally congruent care; however, without appropriate support, their efforts are often subject to improvisation. Healthcare services as well as policymakers should recognise the effect of migration on women's health and the need to address this issue systematically in clinical settings (for example, overcoming the language barrier) or in the community (for example, health promotion and health monitoring throughout the lifespan).

\section{References}

Adanu, R. M., \& Johnson, T. R. (2009). Migration and women's health. International Journal of Gynecology \& Obstetrics, 106(2), 179-181.

AIDOS, ADUSU, \& Culture aperte. (2009). Mutilazioni dei genitali femminili e diritti umani nelle communita migranti: Rapporto di ricerca nelle regioni Veneto e Friuli Venezia Giulia. Retrieved from http://www.aidos.it/wp -content/uploads/2009/01/MGF-rapporto-ricercacomunit\%C3\%Ao -migranti-_ok-1.pdf

Andrews, M. M., \& Boyle, J. S. (2012). Theoretical foundations of transcultural nursing. In M. M. Andrews \& J. S. Boyle (Eds.), Transcultural concepts in nursing care (6th ed., pp. 3-16). Philadelphia, PA:Wolters Kluwer/Lippincott Williams \& Wilkins.

Arousell, J., \& Carlbom, A. (2016). Culture and religious beliefs in relation to reproductive health. Best Practice \& Research: Clinical Obstetrics \& Gynaecology, 32, 77-87. 
Bjarnason, D., Mick, J., Thompson, J. A., \& Cloyd, E. (2009). Perspectives on transcultural care. Nursing Clinics of North America, 44(4), 495-503.

British Sociological Association. (2002). Statement of ethical practice for the British Sociological Association. Retrieved from https://www.britsoc.co.uk/ media/23902/statementofethicalpractice.pdf

de Leon Siantz, M. L. (2013). Feminization of migration: A global health challenge. Global Advances in Health and Medicine, 2(5), 12-14.

Dreachslin, J. L., Gilbert, M. J., \& Malone, B. (2012). Diversity and cultural competence in health care: A systems approach. New York, NY: Wiley.

Fleury, A. (2016). Understanding women and migration: A literature review (Knomad Working Paper 8). Washington, DC: World bank.

Flick, U. (2002). An introduction to qualitative research (2nd ed.). London, England: Sage.

Gibson, W. J., \& Brown, A. (2009). Working with qualitative data. London, England: Sage.

Hargreaves, S., \& Friedland, J. S. (2013). Impact on and use of health services by new migrants in Europe. In F. Thomas \& J. Gideon (Eds.), Migration, health and inequality (pp. 27-43). London, England: Zed Books.

Jayaweera, H. (2018). Access to healthcare for vulnerable migrant women in England: A human security approach. Current Sociology, 66(2), 273-285.

Kim, H., Sefcik, J. S., \& Bradway, C. (2017). Characteristics of qualitative descriptive studies: A systematic review. Research in Nursing \& Health, 40(1), 23-42.

Leininger, M. (2002). The theory of culture care and the ethnonursing research method. In M. Leininger \& M. McFarland (Eds.), Transcultural nursing: Concepts, theories, research and practice (3rd ed., pp. 71-98). New York, NY: McGraw-Hill.

Matthews, B., \& Ross, L. (2010). Research methods: A practical guide for the social sciences. New York, NY: Pearson Longman.

Mengesha, Z. B., Perz, J., Dune, T., \& Ussher, J. (2018). Talking about sexual and reproductive health through interpreters: The experiences of health care professionals consulting refugee and migrant women. Sexual \& Reproductive HealthCare, 16, 199-205.

Merry, L., Vangen, S., \& Small, R. (2016). Caesarean births among migrant women in high-income countries. Best Practice \& Research: Clinical Obstetrics \& Gynaecology, 32, 88-99.

Miles, M. B., \& Huberman, M. A. (1994). Qualitative data analysis: An expanded sourcebook (2nd Ed.). Thousand Oaks, CA: Sage.

Moser, A., \& Korstjens, I. (2018). Series: Practical guidance to qualitative research. Part 3: Sampling, data collection and analysis. European Journal of General Practice, 24(1), 9-18.

Nørredam, M., \& Krasnik, A. (2011). Migrants' access to health services. In B. Rechel, P. Mladovsky, W. Devillé, B. Rijks, R. Petrova-Benedict, \& M. McKee 
(Eds.), Migration and health in the European Union (pp. 67-78). Maidenhead, England: McGraw Hill/Open University Press.

Pace, P. (2011). The right to health of migrants in Europe. In B. Rechel, P. Mladovsky, W. Devillé, B. Rijks, R. Petrova-Benedict, \& M. McKee (Eds.), Migration and health in the European Union (pp. 56-66). Maidenhead, England: McGraw Hill/Open University Press.

Perez Ramirez, F., Garcia-Garcia, I., \& Peralta-Ramirez, M. I. (2013). The migration process as a stress factor in pregnant immigrant women in Spain. Journal of Transcultural Nursing, 24(4), 348-354.

Polit, D. F., \& Beck Tatano, C. (2014). Essentials of nursing research: Appraising evidence for nursing practice (8th ed.). Philadelphia, PA: Wolters Kluwer.

Prosen, M. (2018). Developing cross-cultural competences: Opportunity for ensuring health and healthcare equality and equity. Slovenian Nursing Review, 52(2), 76-80.

Quinn Patton, M. (2015). Qualitative research \& evaluation methods: Integrating theory and practice (4th ed.). Thousand Oaks, CA: Sage.

Reeske, A., \& Razum, O. (2011). Maternal and child health: From conception to first birthday. In B. Rechel, P. Mladovsky, W. Devillé, B. Rijks, R. PetrovaBenedict, \& M. McKee (Eds.), Migration and health in the European Union (pp. 139-153). Maidenhead, England: McGraw Hill/Open University Press.

Repo, H., Vahlberg, T., Salminen, L., Papadopoulos, I., \& Leino-Kilpi, H. (2017). The cultural competence of graduating nursing students. Journal of Transcultural Nursing, 28(1), 98-107.

Riessman, C. K. (2008). Narrative methods for the human sciences. Los Angeles, CA: Sage.

Robertson, E. K. (2015). 'To be taken seriously:' Women's reflections on how migration and resettlement experiences influence their healthcare needs during childbearing in Sweden. Sexual \& Reproductive HealthCare, 6(2), 5965.

Ruppenthal, L., Tuck, J., \& Gagnon, A. J. (2005). Enhancing research with migrant women through focus groups. Western Journal of Nursing Research, 27(6), 735-754.

Saadi, A., Bond, B. E., \& Percac-Lima, S. (2015). Bosnian, Iraqi, and Somali refugee women speak: A comparative qualitative study of refugee health beliefs on preventive health and breast cancer screening. Womens Health Issues, 25(5), 501-508.

Sandelowski, M. (2000). Whatever happened to qualitative description? Research in Nursing \& Health, 23(4), 334-340.

Smith, A. C., LeVoy, M., Mahmood, T., \& Mercer, C. (2016). Migrant women's health issues. Retrieved from http://www.euro.who.int/_data/assets/pdf _file/0017/330092/6-Migrant-womens-health-issues-irregular-status.pdf ?ua $=1$ 
Smythe, E. (2012). Discerning which qualitative approach fits best. New Zealand College of Midwives Journal, 46, 5-12.

Steen, M., \& Roberts, T. (2011). The handbook of midwifery research. Oxford, England: Wiley-Blackwell.

Tsai, T.-I., \& Lee, S.-Y. D. (2016). Health literacy as the missing link in the provision of immigrant health care: A qualitative study of Southeast Asian immigrant women in Taiwan. International Journal of Nursing Studies, 54, 65-74.

World Medical Association. (2013). World Medical Association Declaration of Helsinki: Ethical principles for medical research involving human subjects. Journal of the American Medical Association, 310(20), 2191-2194.

Zbornica zdravstvene in babiške nege Slovenije. 2014. Kodeks etike v zdravstveni negi in oskrbi Slovenije in Kodeks etike za babice Slovenije. Ljubljana, Slovenia: Author.

S. Ličen, I. Karnjuš, \& M. Prosen (Eds.). (2019). Women, migrations and health: Ensuring transcultural healthcare (pp. 117-137). Koper, Slovenia: University of Primorska Press. https://doi.org/10.26493/978-961-7055-43-6.117-137 